\title{
MORFOLOGIA DO VASO DEFERENTE DE Callinectes ornatus (Crustacea: Portunoidea) COLETADOS NO LITORAL SUL CAPIXABA
}

\author{
Marina Lopes Marinho' \\ Jamily Almeida Fontoura ${ }^{2}$ \\ Tugstênio Lima de Souza ${ }^{3}$ \\ Adriane Araújo Braga ${ }^{4}$ \\ Erika Takagi Nunes ${ }^{5}$
}

Resumo: O siri azul (Callinectes ornatus) é um importante recurso pesqueiro, logo conhecer as estruturas que colaboram para seu sucesso reprodutivo é essencial. Este estudo objetivou descrever o vaso deferente dos machos desta espécie de siri, por meio da microscopia de luz. A estrutura do vaso deferente é constituída por três regiões distintas: anterior (VDA) revestido por epitélio cilíndrico simples e, em seu lúmen, é possível notar uma secreção acidófila; média (VDM) possui epitélio cúbico simples e um grande volume de secreção em seu interior; posterior (VDP) que apresenta uma camada muscular bem desenvolvida e vários espermatóforos, encontrados em vários estágios.

Palavras-chave: Reprodução; Histologia; Espermatóforo; Ducto genitais.

\footnotetext{
1 Universidade Federal do Espirito Santo, Brasil. E-mail: marinalopesmarinho@gmail.com.

2 Universidade Federal do Espirito Santo, Brasil. E-mail: jamilyfontoura@gmail.com.

3 Universidade Federal do Espirito Santo, Brasil. E-mail: tugstenio94@hotmail.com.

${ }^{4}$ Universidade Federal do Espirito Santo, Brasil. E-mail: dricrab@yahoo.com.br.

${ }^{5}$ Universidade Federal do Espirito Santo, Brasil. E-mail: erikatnunes@gmail.com.
} 